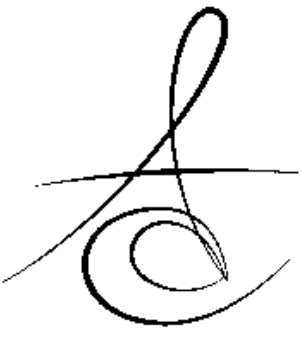

\title{
MANDİBULAR DEFEKTLİ HASTALARIN PROTETİK REHABİLİTASYONUNDA FARKLI TEDAVİ SEÇENEKLERİ : İKİ OLGU SUNUMU
}

\section{DİFFERENT TREATMENT OPTIONS İN PROSTHETIC REHABİLITATION OF PATIEENTS WITTH MANDİBULAR DEFECTS: TWO CASE REPORTS}

\section{Dt. Muhammet KARCI*}

\author{
Yrd. Doç. Dr. Necla DEMİR*
}

Makale Kodu/Article code: 2708

Makale Gönderilme tarihi: 24.03.2016

Kabul Tarihi; 07.04.2016

\section{ABSTRACT}

\section{öz}

Çene ve yüz defektleri konjenital, edinsel veya gelişimsel nedenler sonucu ortaya çıkabilir. Travmatik yaralanmalar veya konjenital malformasyonlar alveolar kemik ve yapışık mukoza kaybına bağlı olarak sert ve yumuşak doku defektlerine sebep olabilir. Defektli alanın restorasyonu klinisyen için çeşitli zorluklar içermektedir.

$\mathrm{Bu}$ olgu sunumunda mandibular defekte sahip iki hastanın farklı tedavi seçenekleri ile protetik rehabilitasyonu anlatılmaktadır. Birinci olguda defektli alan diş destekli sabit protez ile restore edilirken, ikinci olguda defektli alan hareketli protez ile restore edildi.

Hastaların estetik ve fonsiyonel beklentileri karşılandı.

Anahtar kelimeler: Maksillofasial defektler, Hareketli bölümlü protezler, Diş destekli sabit protezler.

\section{GİRİş}

Çene ve yüz defektleri konjenital, edinsel veya gelişimsel nedenler sonucu ortaya çıkabilir. Edinsel defektler arasında travmalar (ateşli silah yaralanmaları, trafik kazaları), tümöral veya kistik oluşumların cerrahi rezeksiyonu ve geç dönemlerinde nekrotizan özelliği olan enfeksiyöz hastalıklar (osteomiyelit, sifiliz) sonucunda oluşan defektler sayılabilir. Dudak-damak yarıkları ve kraniyofasiyal yarıklar konjenital defektler grubuna girerken, sert ve yumuşak doku anomalileri ise gelişimsel defektlere örnek olarak gösterilebilir. ${ }^{1-3}$ Özellikle edinsel olarak oluşan çene-yüz defektlerinin hastalar üzerindeki yıkıcı etkileri oldukça yüksek düzeylerde olmaktadır. Üst çenede oluşan defektler
Maxillofacial defects may be caused by congenital, acquired and developmental factors. Traumatic injuries or congenital malformations may cause soft and hard tissue defects resulting in the loss of alveolar bone and attached mucosa. Restoring the defective area presents a challenge for clinicians.

The prosthetic rehabilitation of 2 patients with mandibular dentoalveolar defects with 2 different prosthetic designs is presented. In the first patient, the defect area was restored with tooth-supported fixed dental prostheses; in the second patient, the defected area was restored with removable dental prostheses.

The esthetic and functional requirements of the patients were fulfilled.

Keywords: Maxillofacial defects, Removable dental prostheses, Tooth-supported fixed dental prostheses.

sonucunda ağız ve burun boşluklarının birbirine açılması veya alt çenede oluşan segmental defektler sonucunda mandibulanın etkilenen tarafa doğru deviyasyon yapması çiğneme, yutkunma, konuşma ve estetik gibi işlevler üzerinde ciddi yetersizliklere neden olmakla kalmayıp, hastayı psikososyal yönden de olumsuz etkilemektedir. Bu defektler cerrahi olarak rekonstrüksiyona tabi tutulduktan sonra protetik yöntemlerle restore edilir. ${ }^{3-5}$ Yumuşak ve sert doku kaybı olduğunda hareketli protezler, diş destekli sabit protezler ve implant destekli sabit protezler gibi farklı tedavi seçenekleri uygulanabilir. ${ }^{6,7}$

$\mathrm{Bu}$ vaka raporunda mandibular dentoalveolar defekte sahip iki hastanın, iki farklı protez ile (diş destekli sabit protez ve hareketli bölümlü protez) tedavisi anlatılmaktadır.

* Selçuk Üniversitesi Diş Hekimliği Fakültesi Protetik Diş Tedavisi Anabilim Dalı 


\section{OLGU SUNUMU OLGU 1}

Alt çene sağ bölgesinden ameloblastik tümör teşhisi ile 2 defa operasyon geçiren 54 yaşındaki erkek hasta, son operasyondan 2 sene sonra estetik ve fonksiyonel zorluklardan dolayı protetik rehabilitasyon için Selçuk Üniversitesi Diş Hekimliği Fakültesi Protetik Diş Tedavisi Anabilim Dalı'na başvurmuştur. Ağız içi muayenesinde alt sağ taraftaki premolar dişler ve birinci molar dişin olmadığı, ayrıca bu bölgedeki alveolar kemikte ve gingival dokularda da kayıp olduğu görüldü (Resim 1). Hastada Class 1 oklüzyon mevcuttu ve geriye kalan dişlerinde sadece alt sol tarafta birinci molar diş eksikliği vardı. Temporomandibular eklem hareketleri semptomatikti ve sağa deviasyon mevcuttu.

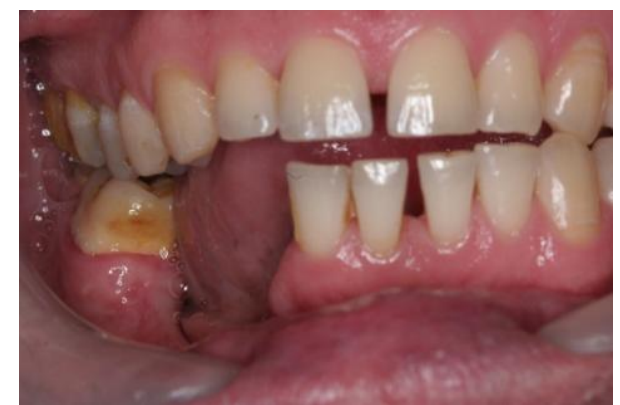

Resim 1. Hastanın tedavisi öncesi ağız içi görünümü

Medikal ve dental hikayesinden sonra radyolojik değerlendirme için dijital panoramik film alındı (Resim 2). Restoratif tedavilerden önce hastanın periodontal tedavisi gerçekleştirildi. Hastaya farklı tedavi seçenekleri anlatıldı (implant destekli sabit protezler, diş destekli sabit protezler ve hareketli protezler). Hastanın hareketli protez kullanımı konusunda isteksiz olması, implant tedavisi için hem maliyetin yüksek olması hem de başka cerrahi işlemlerin gerekmesinden dolayı diş destekli sabit bir restorasyon tercih edildi. Diş preparasyonu bıçak sıtı şeklinde bitirildi ve ölçü polivinilsiloksan ölçü maddesi (Reprosil VPS, Dentsply, Woodbridge, Kanada) ile alındı. Geçici kronlar sıcak akrilik rezinle (Meliodent, Heraeus Kulzer, Almanya ) ile indirekt yöntemle yapıldı. Maddi sebeplerden dolayı zirkonya destekli seramik restorasyon tercih edilmedi. Sol alt kanin dişten sağ alt molar dişe kadar uzanan metal destekli seramik restorasyonlar (Ivoclar Vivadent, Schonn Liechtenstein, Almanya) laboratuvarda hazırlandı. Metal ve dentin provalar yapıldı. Oklüzyon değerlendirildi, prematür kontaklar elimine edildi.
Protezin servikal bitim bölgesi, kaybolan yumuşak dokuyu karşılayabilmek için diş eti rengindeki porselen ile bitirildi. Son olarak restorasyonlar çinko polikarboksilat esaslı siman (Adhesor Carbofine Spofe Dental, Çek Cumhuriyeti) ile simante edildi (Resim 3). Hasta restoratif işlemler sonucunda estetik ve fonksiyon açısından memnun edildi. Hasta düzenli olarak 6 ayda bir kontrole çağrıldı.

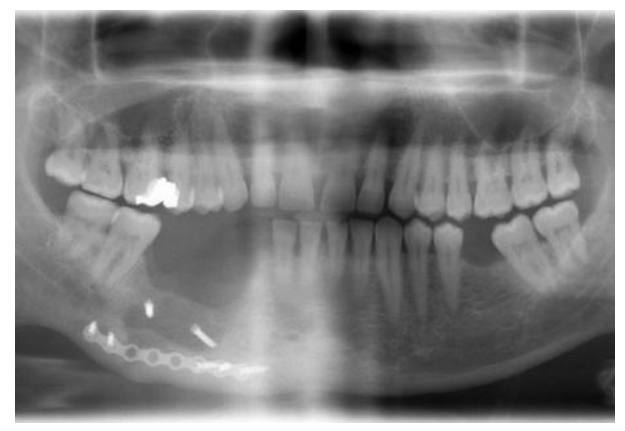

Resim 2. Hastadan alınan dijital panoramik film

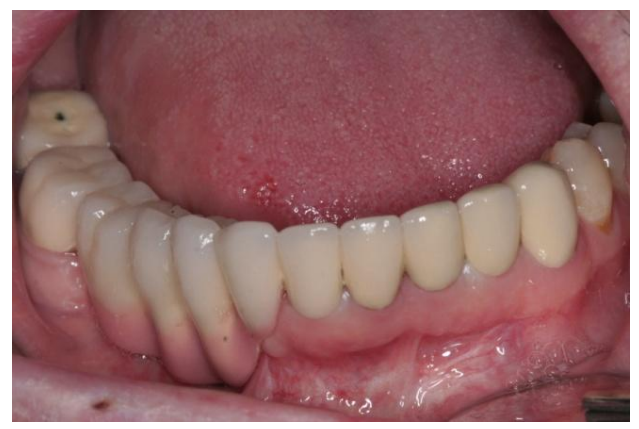

Resim 3. Hastanın tedavi sonrası ağız içi görünümü

\section{OLGU 2}

Alt çene sağ bölgesinden ameloblastik tümör teşhisi ile operasyon geçiren 26 yaşındaki bayan hasta estetik ve fonksiyonel zorluklardan dolayı protetik rehabilitasyon için Selçuk Üniversitesi Diş Hekimliği Fakültesi Protetik Diş Tedavisi Anabilim Dalı'na başvurmuştur. Ağız içi muayenesinde alt orta keserler, sol yan keser, kanin, premolar ve molar dişlerin olmadığı görüldü. Ayrıca kemik ve yumuşak doku kaybı da mevcuttu (Resim 4). Hasta Class 1 oklüzyona sahipti ve temporomandibular eklem asemptomatikti. Bütün tedavi seçenekleri (implant destekli sabit protezler, diş destekli sabit protezler ve hareketli protezler) hastaya anlatıldı ve hasta oral hijyenin daha kolay sağlanması, ucuz olması ve sabit protez endikasyonu olamaması gibi sebeplerden dolayı

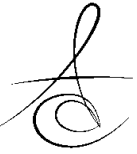


hareketli protez yapımını tercih etti. Hastadan standart ölçü kaşığı ve aljinat ölçü materyali (A37,Cavex, Amsterdam, Hollanda) ile iskelet dökümü için ölçü alındı. İskelet prova yapılıp, dikey boyut ve sentrik ilişki tespiti yapıldı (Resim 5). Daha sonra hareketli proteze akrilik yapay dişler (Vitapan, Vita, Zahnfabrik, Almanya) dizilerek ağızda dişli prova yapıldı. Hastanın da onayı alındıktan sonra laboratuarda muflalama işlemi ile protez bitirildi. Oklüzyon kontrol edildi, polisaj ve bitirme işlemleri yapıldı (Resim 6).

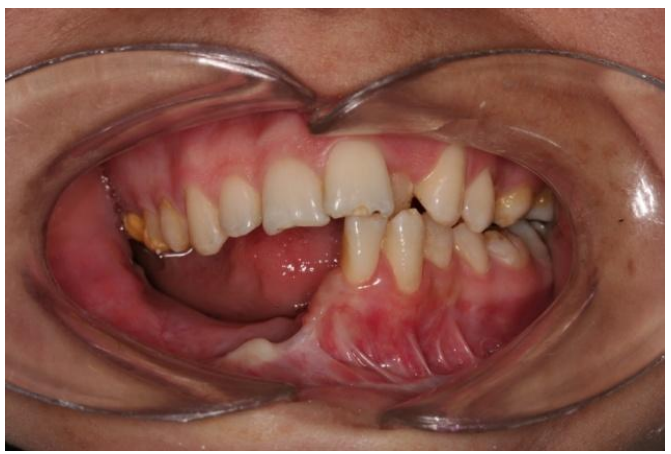

Resim 4. Hastanın tedavi öncesi ağız içi görünümü

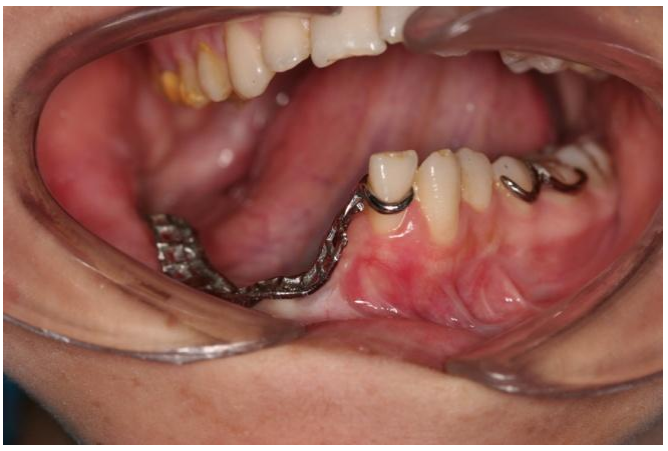

Resim 5. İskelet prova

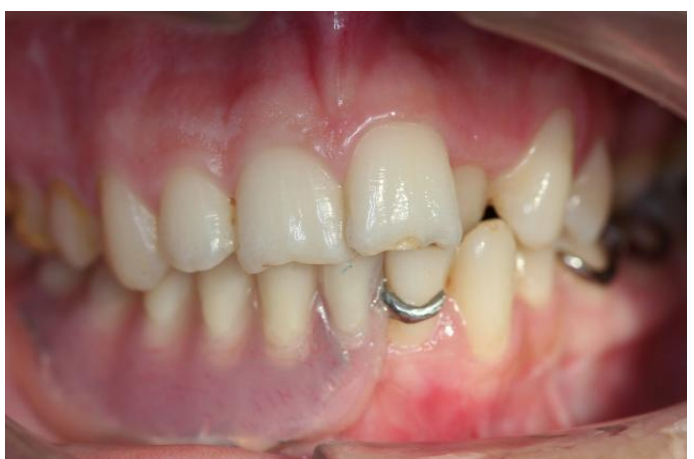

Resim 6. Hastanın tedavisi sonrası ağız içi görünümü

\section{TARTIŞMA}

Maxillofasiyal travmalar araba kazaları, silah yaralanmaları ve tümör veya kistlerin alınması sonucu ortaya çıkabilir ve sıklıkla geniş bir alanda alveolar kemik, dişlerin ve gingival dokuların kaybı ve/veya estetik ve fonksiyonel zorluklara yol açabilir. ${ }^{8,9}$ Bazı hastalar dentoalveolar defektlerin protezlerde yol açtığı retansiyon ve stabilite kaybından dolayı protetik zorluklar çekerler. ${ }^{6,10,11}$

Maksillo-fasiyal protezlerde genel protez kurallarının yanı sıra genellikle her hasta için kendine özgü uygulamalar ve planlamalar yapılmalıdır. ${ }^{12}$ Hareketli protezler; oral hijyeni sağlama kolaylığı, özellikle alveolar sırt ve kemik defekti olduğunda yumuşak doku desteğini sağlanması, maliyetinin ucuz olması, tedavi süresinin kısalması ve takibinin kolay olması gibi avantajlara sahiptir. ${ }^{8}$ Ancak hastaların çoğu bu protezleri sabit protezlere göre daha az estetik olması ve kullanımının daha az konforlu olmasından dolayı kullanmak istemezler. ${ }^{13,14}$ İmplant destekli protezler ise gelişmiş estetik ve biyomekanik avantajlarından dolayı başarılı bir tedavi seçeneği olmuştur. Bunların klinik kullanımlarının artması hareketli protezlerin kullanımını gün geçtikçe daha da azaltmaktadır. ${ }^{15}$ Ancak implant yerleşimi için özellikle defekt alanında komplike cerrahi prosedürler gerekebilir (augmentasyon, distraksiyon, sinüs lifting). ${ }^{16}$

Aynı zamanda implant tedavisi için iyi sistemik ve fizyolojik şartlar, zaman, ekonomik durum, koope rasyon ve sabır gereklidir. ${ }^{8,16}$ Konvansiyonel diş destekli sabit protezler; hala tek ve çoklu diş eksikliklerinin tedavisinde altın standart olarak kabul edilmektedir. İmplant yapımı kontrendike olduğunda veya hasta implant tedavisini reddettiğinde ideal tedavi seçeneği diş destekli sabit protezlerdir. ${ }^{17}$

\section{SONUÇ}

Bu vaka raporu mandibular posterior dişler ve etrafındaki kemik kaybı olan iki hastanın protetik rehabilitasyonunu anlatmaktadır. 6 aylık takip sonucunda her iki hastada herhangi bir gingival, estetik veya fonksiyonel probleme rastlanmadı. Ancak yine de daha uzun süreli takip süresine ihtiyaç duyulmaktadır. 


\section{KAYNAKLAR}

1. Sipahi C, Aydıntuğ YS. Mandibular defektin protetik rehabilitasyonu: olgu sunumu. Gülhane Tıp Derg 2011;53:56-9.

2. Sipahi C. İmplant destekli çene-yüz protezlerinde retansiyon prensipleri. Gülhane Tıp Derg 2006;48: 119-24.

3. Thomas KF. Prosthetic Rehabilitation. 1 ed. London; Quintessence Publishing Co: 1994. p. 169-93.

4. Sipahi C, Ortakoglu K, Ozen J, Caglar A. The prosthodontic restoration of a self-inflicted gunshot maxillofacial defect: a short-term follow-up case report. Int J Prosthodont 2007;20:85-8.

5. Evlioğlu G, Azak A. Edinsel mandibular defektler ve protetik tedavileri. İ.Ü. Diş Hek Fak Derg 2005;39: 37-42.

6. Kourtis S, Psarri C, Andritsakis P, Doukoudakis A. Provisional restorations for optimizing esthetics in anterior maxillary implants: a case report. J Esthet Restor Dent 2007;19:6-17.

7. Ugurlu K, Sacak B, Huthut I, Karsidag S, Sakiz D, Bas $L$. Reconstructing wide palatomaxillary defects using free flaps combining bare serratus anterior muscle fascia and scapular bone. J Oral Maxillofac Surg 2007;65:621-9.

8. Freitas R, Kaizer OB, Hamata MM, de Resende DR, de Oliveira Fortes Kaizer R. Prosthetic rehabilitation of a bone defect with a teeth-implant supported, removable partial denture. Implant Dent 2006;15: 241-7

9. Balshi TJ. Oral prosthodontic rehabilitation for traumatic sports injuries. Dent Clin North Am 1991;35:771-96

10.Ustun Y, Esen E, Toroglu MS, Akova T. Multidisciplinary approach for the rehabilitation of dentoalveolar trauma. Dent Traumatol 2004;20:293-9.

11. Evren BA, Basa S, Ozkan Y, Tanyeri H, Ozkan YK. Prosthodontic rehabilitation after traumatic tooth and bone loss: a clinical report. J Prosthet Dent 2006;95:22-5.

12. Yılmaz $\mathrm{CB}$, Çiftçi $\mathrm{H}$, Yeşil Duymuş Z. Total maksiller rezeksiyonların protetik tedavisi: olgu sunumu. Atatürk Üniv Diş Hek Fak Derg 2015;10:51-5.

13.Frank RP, Brudivik JS, Leroux $B$, Milgrom $P$, Hawkins N. Relationship between the standards of removable partial denture construction, clinical acceptability, and patient satisfaction. J Prosthet Dent 2000;83:521-7.

14. Gokçen-Röhlig B, Atalay B, Baca E, Isik D, Meric U. Prosthetic rehabilitation of a patient with a mandibular defect caused by a gunshot wound. J Craniofac Surg 2009;20:1614-7.

15. Wiens JP. The use of osseointegrated implants in the treatment of patients with trauma. J Prosthet Dent 1992;67:670-8.

16.Ozkurt Z, Kazazoglu E. Treatment modalities for single missing teeth in a Turkish subpopulation: an implant, fixed partial denture, or no restoration. J Dent Sci 2010;5:183-8.

17.Canpolat C, Özkurt-Kayahan Z, Kazazoglu E. Prosthetic rehabilitation of maxillary dentoalveolar defects with fixed dental prostheses: Two clinical reports. J Prosthet Dent 2014;112:418-422.

\section{Yazışma Adresi}

Dt. Muhammet KARCI

Selçuk Üniversitesi Diş Hekimliği Fakültesi

Protetik Diş Tedavisi Anabilim Dalı

SELÇUKLU/KONYA

3322231186

e-mail: muhammetdt48@hotmail.com 